\title{
Synergistic antidepressant- and anxiolytic-like effects of harmaline along with cinanserin in acute restraint stress-treated mice
}

\author{
Sajedeh Mosaffa ${ }^{1} \cdot$ Hanieh Ahmadi ${ }^{1}$. Fatemeh Khakpai ${ }^{2} \cdot$ Mohaddeseh Ebrahimi-Ghiri $^{3}$. \\ Mohammad-Reza Zarrindast ${ }^{1,4,5}$
}

Received: 6 June 2020 / Accepted: 7 October 2020 / Published online: 14 November 2020

(C) Springer-Verlag GmbH Germany, part of Springer Nature 2020

\begin{abstract}
Rationale Acute restraint stress (ARS) is an experimental paradigm used for the induction of rodent models of stress-produced neuropsychiatric disorders, such as depression and anxiety. $\beta$-carbolines and serotonin (5-HT) systems are involved in the modulation of depression and anxiety behaviors.

Objective This study was designed to examine the effects of intracerebroventricular (i.c.v.) injection of cinanserin (5-HT2 receptor antagonist) on harmaline-induced responses on depression- and anxiety-like behaviors in the ARS mice.

Methods For i.c.v. infusion, guide cannula was surgically implanted in the left lateral ventricle of mice. The ARS model was conducted via movement restraint at a period of $4 \mathrm{~h}$. Depression- and anxiety-related behaviors were evaluated by forced swim test (FST) and elevated plus maze (EPM), respectively.

Results The results displayed that the ARS mice showed depressive- and anxiety-like responses. I.p. administration of different doses of harmaline $(0.31,0.625$ and $1.25 \mathrm{mg} / \mathrm{kg})$ or i.c.v. microinjection of cinanserin $(1,2.5$, and $5 \mu \mathrm{g} / \mathrm{mouse})$ blocked depression- and anxiogenic-like behaviors in the ARS mice. Furthermore, co-administration of harmaline (1.25 mg/kg; i.p.) and cinanserin $(5 \mu \mathrm{g} /$ mouse; i.c.v.) prevented the depression- and anxiogenic-like effects in the ARS mice. We found a synergistic antidepressant- and anxiolytic-like effects of harmaline and cinanserin in the ARS mice.

Conclusions These results propose an interaction between harmaline and cinanserin to prevent depressive- and anxiogenic-like behaviors in the ARS mice.
\end{abstract}

Keywords Acute restraint stress (ARS) $\cdot$ Harmaline $\cdot$ Cinanserin $\cdot$ Depression $\cdot$ Anxiety

\section{Introduction}

$\beta$-Carboline alkaloids are a class of alkaloids that have prompted substantial investigation interest (Pfau and Skog

Mohammad-Reza Zarrindast

zarinmr@ams.ac.ir

1 Department of Pharmacology, School of Medicine, Tehran University of Medical Sciences, P.O.Box 13145-784, Tehran, Iran

2 Cognitive and Neuroscience Research Center (CNRC), Tehran Medical Sciences, Islamic Azad University, Tehran, Iran

3 Department of Biology, Faculty of Sciences, University of Zanjan, Zanjan, Iran

4 Iranian National Center for Addiction Studies, Tehran University of Medical Sciences, Tehran, Iran

5 Department of Neuroendocrinology, Endocrinology and Metabolism Clinical Sciences Institute, Tehran University of Medical Sciences, Tehran, Iran
2004). In nature, $\beta$-carbolines are found in some of the plants, including Banisteriopsis caapi (Malpighiaceae) and Peganum harmala L. (Zygophyllaceae) (Callaway et al. 2005). The probable use of Peganum harmala in modern phyto-indole entheogen preparations is related to its content of $\beta$-carbolines: harmine, harmaline, and tetrahydroharmine (Glennon et al. 2000). Harmaline commonly identified to provoke motor variations via activation of cells in the inferior olive (Hilber and Chapillon 2005). Besides, studies revealed that harmaline has antidepressive and anxiolytic properties that seem to be mediated by MAO inhibition and modulation of serotonin (5-HT), benzodiazepine, and dopamine receptors (Abelaira et al. 2013; Dos Santos et al. 2016a; Dos Santos et al. 2016b; Savoldi et al. 2017; Splettstoesser et al. 2005). Interestingly, harmaline is endogenously produced in human and animal tissues as a low-molecular-weight product of secondary metabolism ( $\mathrm{Li}$ et al. 2017b, c; Moloudizargari et al. 2013). 
Stress is defined as a general response to any environmental stressors (both internal and external) upon the body and is accompanied by many physiological and psychological variations including depression and anxiety (de Kloet et al. 2005; Herman et al. 2012; Li et al. 2012). Depressive and anxiety disorders are the most common psychiatric conditions in clinical studies. These disorders need a broad therapeutic approach so that it should balance benefits and adverse properties or other potentially detrimental properties of medications (Kolar and Kolar 2016; Tiller 2013). Anxiety-like behaviors, along with depressive-like actions, can be produced using various paradigms such as acute and constant stress exposure, prolonged stress, chronic social defeat, and pre/post-natal stress (Bailey and Crawley 2009). The 5-HT system has been widely implicated in depression and anxiety disorders, which indicate the most common, and costly psychiatric disorders. This system is a various and intricate system which consisted of at least 15 recognized receptor subtypes (Abrams et al. 2004; Cunningham et al. 2019; Guiard and Di Giovanni 2015; Hill et al. 2006). Pharmacological and genetic researches have highlighted the central role of 5-HT2A receptors in specific brain pathologies such as depression and anxiety (Quesseveur et al. 2012). 5-HT2A receptors are members of the metabotropic seven transmembrane-spanning receptors superfamily, frequently referred to as $\mathrm{G}$ protein-coupled receptors (Guiard and Di Giovanni 2015). Particularly, 5-HT2A receptors belong to the 5-HT2 subfamily consisting, with 5HT2B and 5-HT2C, of three Gq/G11-coupled receptors, that exert excitatory neurotransmission (Millan et al. 2008). The 5HT2 receptor subtypes have warranted attention in depression and anxiety as well as the mechanism of action of correlated treatments. They couple to various cellular signaling pathways and participate in the modulation of a variety of physiological brain functions so constituting therapeutic targets for psychiatric disorders such as depression and anxiety (Celada et al. 2004; Jensen et al. 2010; Leysen 2004). In the rodent brain, 5 HT2 receptors have an extensive distribution, mainly in monoaminergic regions (Quesseveur et al. 2012).

Based on psychopharmacological properties of harmaline and its binding to the 5-HT2 receptor (Dos Santos et al. 2016a), we hypothesized that the 5-HT2 receptor possibly mediates harmaline signaling in the brain. Thus, the present study was designed to investigate whether blocking 5-HT2 receptors can influence harmaline-modified depression- and anxiety-like behaviors on acute restraint stress (ARS) condition using forced swim test (FST) and elevated plus maze (EPM) in mice.

\section{Materials and methods}

\section{Animals}

Adult male NMRI mice (6-8 weeks old, weighing 20-25 g) were obtained from the Tehran University of medical sciences
(Pharmacology Department, Tehran, Iran). Animals were kept in groups under standard conditions (12-h light/dark cycle; 22 $\pm 2{ }^{\circ} \mathrm{C}$ ambient temperature; $55 \pm 10 \%$ relative humidity) and were allowed to adapt 1 week. Mice were handled during this 1 week prior to the experiments to reduce the stress produced for experimental manipulations and were fed with standard diet and water ad libitum. Behavioral observations and analysis were done by experimenters who were unaware of the mice treatments. The experimental protocols involving animals and their care were conducted in compliance with the Research and Ethics Committee of Tehran University of Medical Sciences. They were performed upon the National Institutes of Health Guide for the Care and Use of Laboratory Animals (NIH publications No. 80-23).

\section{Surgery and microinjection procedures}

To central infusion of drugs, mice were implanted with a 22-gauge stainless steel guide cannula aimed at the lateral ventricle. Implantation was done under ketamine-xylazine (100 mg/kg ketamine-5 mg/kg xylazine mixture, intraperitoneally (i.p.)) anesthesia, and was performed at least 1 week prior to the behavioral tests. Stereotaxic coordinates for the left lateral ventricle were as follows: anteroposterior $(\mathrm{AP})=-0.9 \mathrm{~mm}$ from the bregma; mediolateral $=-1.5 \mathrm{~mm}$ from the sagittal suture; and dorsoventral $=-2 \mathrm{~mm}$ from the skull surface (Paxinos and Franklin 2001). The cannula was subsequently fixed to the skull by one screw and dental acrylic. A stylet was inserted within the cannula to preserve its patent before infusions. Drug infusions were done by a 27 -gauge stainless steel needle (1 mm longer than the guide cannula) attached to a Hamilton micro-syringe via polyethylene tubing. The mice were gently held by hand; infusions lasted for $60 \mathrm{~s}$ and the cannula was left in place for an additional $60 \mathrm{~s}$ to avoid the backflow of the solution. Before the experiments, the mice had at least 5-7 days recovery period.

\section{Drugs}

The following compounds were tested: cinanserin hydrochloride, $5-\mathrm{HT}_{2 \mathrm{~A}}$ and $5-\mathrm{HT}_{2 \mathrm{C}}$ receptor antagonist, $(1,2.5$, and $5 \mu \mathrm{g} /$ mouse; Tocris, UK), and harmaline hydrochloride $(0.31,0.625$, and $1.25 \mathrm{mg} / \mathrm{kg}$; Sigma, USA). Both drugs were dissolved in sterile $0.9 \%$ saline. Cinanserin and harmaline were administered intracerebroventricularly (i.c.v.; a volume of $1 \mu \mathrm{l} /$ mouse) and intraperitoneally (i.p.; a volume of $10 \mathrm{ml} /$ $\mathrm{kg}$ ), respectively. The doses of the drugs and the route of drug administration were selected upon our previous studies (Nasehi et al. 2017a; Nasehi et al. 2014). 


\section{Procedures}

\section{Acute restraint stress induction}

Acute restraint stress (ARS) was conducted through movement restraint at a period of $4 \mathrm{~h}$ (Vargas-Lopez et al. 2015). Mice randomly assigned to be submitted to stress were quietly located in 50-ml (Falcon) plastic tubes, packing with paper tissue at the rear for $4 \mathrm{~h}$; these were designed to restrain major head and limb movement. Mice were allowed to get out of the restrainers $30 \mathrm{~min}$ before experimental tests and to move freely around their home cages to evade non-particular motor effects due to movement restriction.

\section{Forced swimming test}

Forced swimming test (FST) was used to assess depressionlike behavior. The apparatus was made of a cylindrical glass container (25-cm height, $10-\mathrm{cm}$ diameter) filled with $19 \mathrm{~cm}$ of water at $25{ }^{\circ} \mathrm{C}$. Each animal was located in the container for $6 \mathrm{~min}$. Since great agitation is commonly observed during the first 2 min, only the immobility times happening during the last 4 min were calculated. An animal was recognized immobile when it ceased its swimming tries and continued floating motionless in the water, making only those movements required to keep its head above water (Alijanpour et al. 2019).

\section{Elevated plus maze test}

The elevated plus maze (EPM) test was done to assess the anxiety-like behavior of the mice. The EPM apparatus, made of dark Plexiglas, was cross-shaped and comprised of a central platform $(5 \times 5 \mathrm{~cm})$ with two open arms $(30 \times 5 \mathrm{~cm})$ opposite to each other as well as two equal-sized enclosed $(30 \times 5 \times$ $15 \mathrm{~cm}$ ) arms opposite to each other. The EPM apparatus was elevated to the height of $50 \mathrm{~cm}$ above the floor and illuminated via dim light. The protocol was selected upon our recently published data (Nejati et al. 2020). Mice were located in the center of the apparatus with their head facing an open arm. During the 300 -s observation period, the numbers of entries to the open and closed arms were measured, and the time which each mouse spent on the open arm was calculated. The entry into one arm was recognized as the stage when the mouse located all of four paws past the line, which divided the central square from the open arms. The time spent in open arms (OAT) and the number of entries to the open arms (OAE) were used as an amount for anxiety. Also, the number of total arm entries was used as an amount for locomotor activity.

\section{Experimental design}

Eight mice were used in each experimental group and all mice were naive to the experimental test. In the NARS groups, mice received i.p. injection of drugs 30 min before behavioral tests and i.c.v. microinjection of drugs $10 \mathrm{~min}$ before the behavioral tests. In the ARS groups, mice have conducted the stress procedure for $4 \mathrm{~h}$. After $30 \mathrm{~min}$ of rest, they received i.p. administration of saline $(10 \mathrm{ml} / \mathrm{kg})$ or different doses of harmaline. i.c.v. injection of saline $(2.5 \mu \mathrm{g} /$ mouse $)$ or different doses of cinanserin was performed $20 \mathrm{~min}$ after i.p. administration. Ten minutes after the second administration, mice were submitted to the EPM and then FST apparatus. There was a 10-min interval between two behavioral tests.

\section{Experiment 1}

In this experiment, the effect of harmaline administration on depression- and anxiety-like behaviors was examined in the NARS and ARS mice using the EPM and FST. Four groups of mice were included NARS which were injected with saline or different doses of harmaline $(0.31,0.625$, and $1.25 \mathrm{mg} / \mathrm{kg}$; i.p.). The other four groups included ARS mice which received the same doses of the drug. Table 1 explains the protocol and experimental groups.

\section{Experiment 2}

This experiment examined the effect of cinanserin microinjection on depression-like and anxiety-like behaviors in the NARS and ARS mice. Eight groups of mice were used in which four groups of them included NARS and the other four groups included ARS mice. Mice were microinjected with saline or different doses of cinanserin $(1,2.5$, and $5 \mu \mathrm{g} /$ mouse; i.c.v.).

\section{Experiment 3}

In this experiment, the effect of harmaline and cinanserin coadministration on depression-like and anxiety-like behaviors was assessed in the NARS and ARS mice. Seven groups of mice were used. Two groups of mice included NARS and received saline (10 $\mathrm{mg} / \mathrm{kg}$; i.p.) and cinanserin ( $5 \mu \mathrm{g} / \mathrm{mouse}$; i.c.v.). Five groups of mice included ARS mice which received saline (10 mg/kg; i.p.), cinanserin (5 $\mu \mathrm{g} / \mathrm{mouse}$; i.c.v.), and co-administration of different doses of harmaline (0.31, 0.625, and $1.25 \mathrm{mg} / \mathrm{kg}$; i.p.) along with cinanserin (5 $\mu \mathrm{g}$ /mouse; i.c.v.).

\section{Experiment 4}

To confirm whether harmaline and cinanserin coadministration would exert additive or synergistic effects on their induced effects, the isobolographic analysis was done to compare the theoretical and experimental ED50 of the drugs when administrated together. According to the dose-response curve of harmaline and cinanserin, mice of ARS received 
Table 1 The table clarified experimental groups

\begin{tabular}{|c|c|c|c|c|c|}
\hline Experiment & Figure & Stress & Drug treatments & Effect on anxiety & Effect on depression \\
\hline \multirow[t]{2}{*}{1} & Left & NARS & Harmaline $(0,0.31,0.625$, and $1.25 \mathrm{mg} / \mathrm{kg}$; i.p. $)$ & - & - \\
\hline & Right & ARS & Harmaline $(0,0.31,0.625$, and $1.25 \mathrm{mg} / \mathrm{kg}$; i.p. $)$ & Anxiolytic & Antidepressant \\
\hline \multirow[t]{2}{*}{2} & Left & NARS & Cinanserin $(0,1,2.5$, and $5 \mu \mathrm{g} /$ mouse; i.c.v. $)$ & - & - \\
\hline & Right & ARS & Cinanserin $(0,1,2.5$, and $5 \mu \mathrm{g} /$ mouse; i.c.v. $)$ & Anxiolytic & Antidepressant \\
\hline \multirow[t]{2}{*}{3} & - & NARS & Cinanserin $(0$ and $5 \mu \mathrm{g} / \mathrm{mouse}$; i.c.v. $)$ & - & - \\
\hline & & ARS & $\begin{array}{l}\text { Cinanserin }(0 \text { and } 5 \mu \mathrm{g} / \mathrm{mouse} \text {; i.c.v. }) \text {, harmaline } \\
(0.31,0.625 \text {, and } 1.25 \mathrm{mg} / \mathrm{kg} \text {; i.p. })+\text { cinanserin } \\
(5 \mu \mathrm{g} / \text { mouse; i.c.v. })\end{array}$ & Anxiolytic & Antidepressant \\
\hline \multirow[t]{9}{*}{4} & A & ARS & Harmaline $(0.31 \mathrm{mg} / \mathrm{kg})+$ cinanserin $(2.5 \mu \mathrm{g} /$ mouse $)$ & Synergistic anxiolytic & Synergistic antidepressant \\
\hline & & & Harmaline $(0.155 \mathrm{mg} / \mathrm{kg})+$ cinanserin $(1.25 \mu \mathrm{g} /$ mouse $)$ & & \\
\hline & & & Harmaline $(0.077 \mathrm{mg} / \mathrm{kg})+$ cinanserin $(0.625 \mu \mathrm{g} /$ mouse $)$ & & \\
\hline & $\mathrm{B}$ & ARS & Harmaline $(0.31 \mathrm{mg} / \mathrm{kg})+$ cinanserin $(2.5 \mu \mathrm{g} /$ mouse $)$ & Synergistic anxiolytic & Synergistic antidepressant \\
\hline & & & Harmaline $(0.155 \mathrm{mg} / \mathrm{kg})+$ cinanserin $(1.25 \mu \mathrm{g} /$ mouse $)$ & & \\
\hline & & & Harmaline $(0.077 \mathrm{mg} / \mathrm{kg})+$ cinanserin $(0.625 \mu \mathrm{g} /$ mouse $)$ & & \\
\hline & $\mathrm{C}$ & ARS & Harmaline $(0.31 \mathrm{mg} / \mathrm{kg})+$ cinanserin $(2.5 \mu \mathrm{g} /$ mouse $)$ & Synergistic anxiolytic & Synergistic antidepressant \\
\hline & & & Harmaline $(0.155 \mathrm{mg} / \mathrm{kg})+$ cinanserin $(1.25 \mu \mathrm{g} / \mathrm{mouse})$ & & \\
\hline & & & Harmaline $(0.077 \mathrm{mg} / \mathrm{kg})+$ cinanserin $(0.625 \mu \mathrm{g} /$ mouse $)$ & & \\
\hline
\end{tabular}

harmaline $0.31 \mathrm{mg} / \mathrm{kg}+$ cinanserin $2.5 \mu \mathrm{g} / \mathrm{mouse}$, harmaline $0.155 \mathrm{mg} / \mathrm{kg}+$ cinanserin $1.25 \mu \mathrm{g} / \mathrm{mouse}$, and harmaline $0.077 \mathrm{mg} / \mathrm{kg}+$ cinanserin $0.625 \mu \mathrm{g} / \mathrm{mouse}$ (Nasehi et al. 2016; Nasehi et al. 2017b; Nejati et al. 2020).

\section{Histology}

At the end of tests, mice were deeply anesthetized and methylene blue solution ( $1 \%, 0.3 \mu \mathrm{l} /$ mouse) was infused into the guide cannula for the verification of cannula location (Fig. 1). The brain of each mouse was removed and located in formaldehyde (10\%). After 7-10 days, the brain sections were histologically assessed according to the atlas of Paxinos and Franklin (Paxinos and Franklin 2001). A cannula was implanted into the left ventricle of a total of 215 mice; however, only the data from 208 mice with correct cannula implants were included in the statistical analyses.

\section{Data analysis}

Statistical analyses were done using the SPSS statistical package. The results are expressed as mean \pm S.E.M. The statistical analysis was done by one-way and two-way analysis of variance (ANOVA). Post hoc comparison of means was performed by the Tukey test for multiple comparisons, when appropriate. The level of statistical significance was considered at $P<0.05$.

Furthermore, isobolographic analysis was done to identify the interactions following the administration of the two drugs (Nasehi et al. 2016, 2017b; Nejati et al. 2020). The ED50 of each drug $(0.31 \mathrm{mg} / \mathrm{kg}$ for harmaline and $2.5 \mu \mathrm{g} / \mathrm{mouse}$ for cinanserin) was analyzed by linear regression analysis and a combination of the two drugs was administrated in a constant dose ratio based on the ED50 values. For drug combinations, the theoretic ED50 is harmaline ED50/2 + cinanserin ED50/2. Additionally, experimental values of drug combinations from fixed ratio-calculated were measured by the regression analysis, after which the experimental ED50 value of the drug combinations was recognized (\%50 OAT, OAE, and FST). The statistical significance of the difference between theoretical ED50 and experimental ED50 of drug combinations was documented using the one-sample $t$ test. When the experimental ED50 was significantly lower than the theoretical ED50, a synergistic interaction between harmaline and cinanserin could be concluded. Nonetheless, there was not any difference between them presenting additive interaction rather than the synergistic effect (Nasehi et al. 2016, 2017b; Nejati et al. 2020). Differences with $P<0.05$ between the experimental groups at each point were exhibited statistically significant.

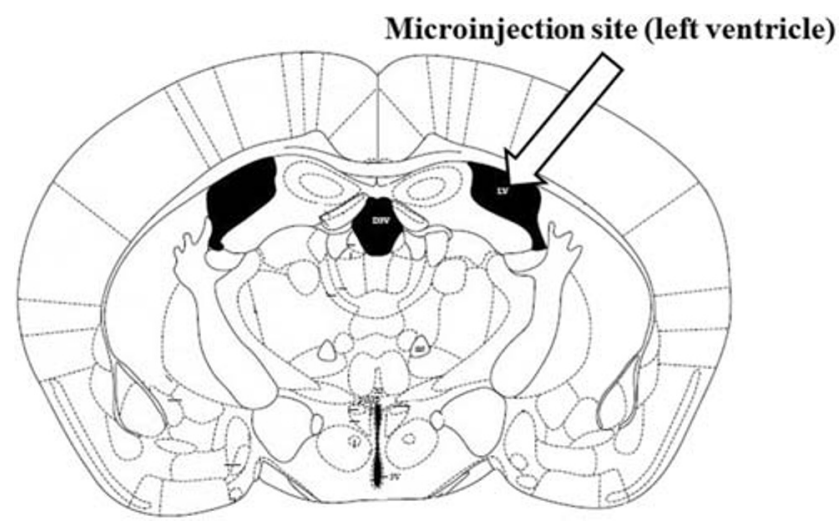

Fig. 1 Approximate location of the injection cannula tip in the left lateral ventricle for all mice included in the data analyses was taken from the atlas of Paxinos and Franklin (Paxinos and Franklin 2001) 


\section{Results}

\section{Depressive- and anxiety-like behaviors induced by ARS were abolished by harmaline}

The effects of harmaline $(0.31,0.625$, and $1.25 \mathrm{mg} / \mathrm{kg}$; i.p.) on depression- and anxiety-like behaviors in the non-ARS (NARS) and ARS mice are seen in Fig. 2. Two-way ANOVA showed a significant difference between harmaline and immobility time in the FST (treatment effect: $F(1,56)=$ $1.309, P=0.257$; dose effect: $F(3,56)=0.913, P=0.441$, treatment-dose interaction: $F(3,56)=4.517, P=0.007$; Fig. 2(A)), OAT in the EPM (treatment effect: $F(1,56)=0.014$, $P=0.906$; dose effect: $F(3,56)=2.822, P=0.042$, treatment-dose interaction: $F(3,56)=4.799, P=0.005$; Fig. 2(B)), but not for OAE (treatment effect: $F(1,56)=5.139$, $P=0.027$; dose effect: $F(3,56)=0.337, P=0.798$, treatment-dose interaction: $F(3,56)=0.064, P=0.978$; Fig. $2(\mathrm{C}))$ and locomotor activity (treatment effect: $F(1,56)=$ 1.143, $P=0.116$; dose effect: $F(3,56)=1.492, P=0.227$, treatment-dose interaction: $F(3,56)=0.511, P=0.676$; Fig. 2(D)). Post hoc analysis exhibited that ARS, at a period of $4 \mathrm{~h}$, enhanced immobility time in the FST while reduced OAT in the EPM in comparison with the saline group, presenting depression- and anxiety-like behaviors in mice. ARS mice significantly decreased OAT while they did not alter OAE in the EPM compared to the NARS mice. Stress appears to reduce mice's tendency to stay in open arms, suggesting an anxiogenic-like behavior. On the other hand, the curiosity to discover new environments causes them to enter open arms. Moreover, harmaline at doses of 0.625 and $1.25 \mathrm{mg} / \mathrm{kg}$ decreased immobility time in the FST whereas at doses of 0.31 and $0.625 \mathrm{mg} / \mathrm{kg}$ increased OAT in the EPM in comparison to control and respective control groups. Thus, harmaline reversed ARS-induced depression- and anxiety-like behaviors in the ARS mice. It seems that in the NARS mice, increasing doses of harmaline produced an increase in immobility time in the FST, but they were not significant.

\section{Cinanserin abolished depressive- and anxiety-like behaviors induced by ARS}

Figure 3 displayed the effects of cinanserin $(1,2.5$, and $5 \mu \mathrm{g} /$ mouse; i.c.v.) on depressive- and anxiety-like behaviors in the NARS and ARS mice. Two-way ANOVA exhibited a meaningful difference between cinanserin and immobility time in the FST (treatment effect: $F(1,56)=1.053, P=0.103$; dose effect: $F(3,56)=3.569, P=0.020$; treatment-dose interaction: $F(3,56)=3.128, P=0.035$; Fig. 3(A)), OAT in the EPM (treatment effect: $F(1,56)=0.009, P=0.967$; dose effect: $F(3,56)=2.834, P=0.046$; treatment-dose interaction: $F(3,56)=2.998, P=0.045$; Fig. 3(B)), but not for OAE (treatment effect: $F(1,56)=1.131, P=0.292$; dose effect: $F$
$(3,56)=0.488, P=0.692$; treatment - dose interaction: $F(3$, $56)=0.052, P=0.980$; Fig. $3(\mathrm{C}))$ and locomotor activity (treatment effect: $F(1,56)=1.699, P=0.660$; dose effect: $F$ $(3,56)=0.899, P=0.452$; treatment - dose interaction: $F(3$, $56)=0.283, P=0.837$; Fig. 3(D)). Moreover, post hoc analysis revealed that ARS (for $4 \mathrm{~h}$ ) increased immobility time in the FST but decreased OAT in the EPM compared to saline group, showing depressive- and anxiogenic-like behaviors. In addition, all doses of cinanserin $(1,2.5$, and $5 \mu \mathrm{g} /$ mouse $)$ decreased immobility time in the FST whereas it increased OAT of ARS mice compared to control and respective groups. So, cinanserin abolished ARS-produced depression- and anxiogenic-related behaviors in the ARS mice.

\section{Cinanserin potentiated the harmaline response on ARS-induced depressive- or anxiety-like behaviors}

In Fig. 4 are seen the effects of different doses of harmaline alone or in the presence of cinanserin on the performance of the ARS mice in the FST and EPM. One-way ANOVA and post hoc analysis exhibited that co-treatment of harmaline $(1.25 \mathrm{mg} / \mathrm{kg}$; i.p. $)$ and cinanserin $(5 \mu \mathrm{g} / \mathrm{mouse}$; i.c.v. $)$ declined immobility time in the FST $(F(6,49)=8.172, P=0.000$; Fig. $4(\mathrm{~A}))$, while it enhanced OAT $(F(6,49)=8.517, P=0.000$; Fig. 4(B) $)$ and $\operatorname{OAE}(F(6,49)=6.191, P=0.000$; Fig. $4(\mathrm{C}))$ in comparison with saline, cinanserin, and ARS groups. Furthermore, these administrations did not alter locomotor activity $(F(6,49)=1.113, P=0.369$; Fig. $4(D))$. As a result, co-administration of harmaline $(1.25 \mathrm{mg} / \mathrm{kg})$ and cinanserin ( $5 \mu \mathrm{g} /$ mouse) abrogated depression- and anxiogenic-like behaviors induced by ARS.

\section{There is a synergistic effect between harmaline and cinanserin on the reduction of depression- and anxiogenic-like behaviors induced by ARS}

The theoretical additive line exhibited that at all points, harmaline and cinanserin combination caused an effect of theoretical \%50 FST and theoretical \%50 OAT as well as theoretical \%50 OAE (theoretical ED50) according to an additive interaction (Fig. 5). One sample $t$ test indicated that there is a significant difference between the experimental ED50 and theoretical ED50. The results of the present study proposed a synergistic effect of harmaline and cinanserin coadministration upon induction of antidepressant- and anxiolytic-like effects in the ARS mice (Fig. 5).

\section{Discussion}

The results of the current study revealed that (i) ARS (for $4 \mathrm{~h}$ ) induced depressant-like and anxiogenic-like responses in the FST and EPM, respectively; (ii) harmaline and cinanserin 
Fig. 2 The effects of harmaline on depression- and anxiety-related behaviors in the NARS and ARS mice using the EPM and FST. (A) ARS (for $4 \mathrm{~h}$ ) increased immobility time in the FST compared to the saline group. Also in ARS-treated mice, i.p. administration of harmaline at doses of 0.625 and $1.25 \mathrm{mg} / \mathrm{kg}$ reduced immobility time in the FST in comparison to control and respective control groups. (B) Harmaline $(0.31$ and $0.625 \mathrm{mg} / \mathrm{kg}$; i.p.) increased OAT of ARS mice in comparison with control and respective control groups. (C) Different doses of harmaline did not affect OAE compared to the control group. (D) Diverse doses of harmaline did not change locomotor activity in the EPM compared to the control group. Data are expressed as means $\pm \operatorname{SEM}$ ( $n=8$ mice/group). $* * * p<0.001, * * p<0.01$, and $* p<0.05$ in comparison to saline/saline group. $++p<0.01$ and $+p<0.05$ in compared with the saline/harmaline group

prevented depressive- and anxiogenic-like behaviors in the ARS mice; and (iii) there is a synergistic effect between harmaline and cinanserin on the modulation of depressionand anxiety-like behaviors in acute stress condition.

This work found that acute restraint stress (at a period of $4 \mathrm{~h}$ ) administered before experimental tests caused depressiveand anxiety-like behaviors in mice. Induction of depressionand anxiogenic-like behaviors in the FST and EPM produced by ARS was not attributable to changes in locomotor activity of FST or to a decreased tendency to explore in the open arms of EPM, because there were no significant differences regarding control mice in either the locomotor activity (swimming) in the FST as well as through enclosed and open arms of EPM. Stress that we experience in our daily lives starts a variety of physiological processes of the central and peripheral systems. Nevertheless, exaggerated and prolonged central and peripheral system responses to chronic excessive stress are considered to be related to the pathogenesis of neuropsychiatric disorders such as depression and anxiety (de Kloet et al. 2005; Herman et al. 2012; Li et al. 2012). According to our results, many reports are showing that acute and chronic exposure to restraint stress induces multiple physiological and behavioral changes, such as heightened depression-related and anxietylike behaviors (Chiba et al. 2012; Christiansen et al. 2011; Grizzell et al. 2014; Shoji and Miyakawa 2020; Voorhees et al. 2013).

The result of this study showed that i.p. injection of harmaline abolished ARS-induced depression- and anxiogenic-like behaviors in the ARS mice. Harmaline has attracted much attention to its biological activities, and its suggested use for the treatment of neurological disorders based on an activity as inhibitors of MAO (Khan et al. 2004; Li et al. 2017a, c). A growing body of studies revealed that harmaline has antioxidant, neuroprotective, antidepressive, anxiolytic, and antiaddictive properties. These effects were mediated by MAO and acetylcholinesterase inhibition; regulation of the dual-specificity tyrosine-phosphorylationregulated kinase; modulation of 5-HT, benzodiazepine, dopamine, GABA, and opiate receptors; interaction with voltage-

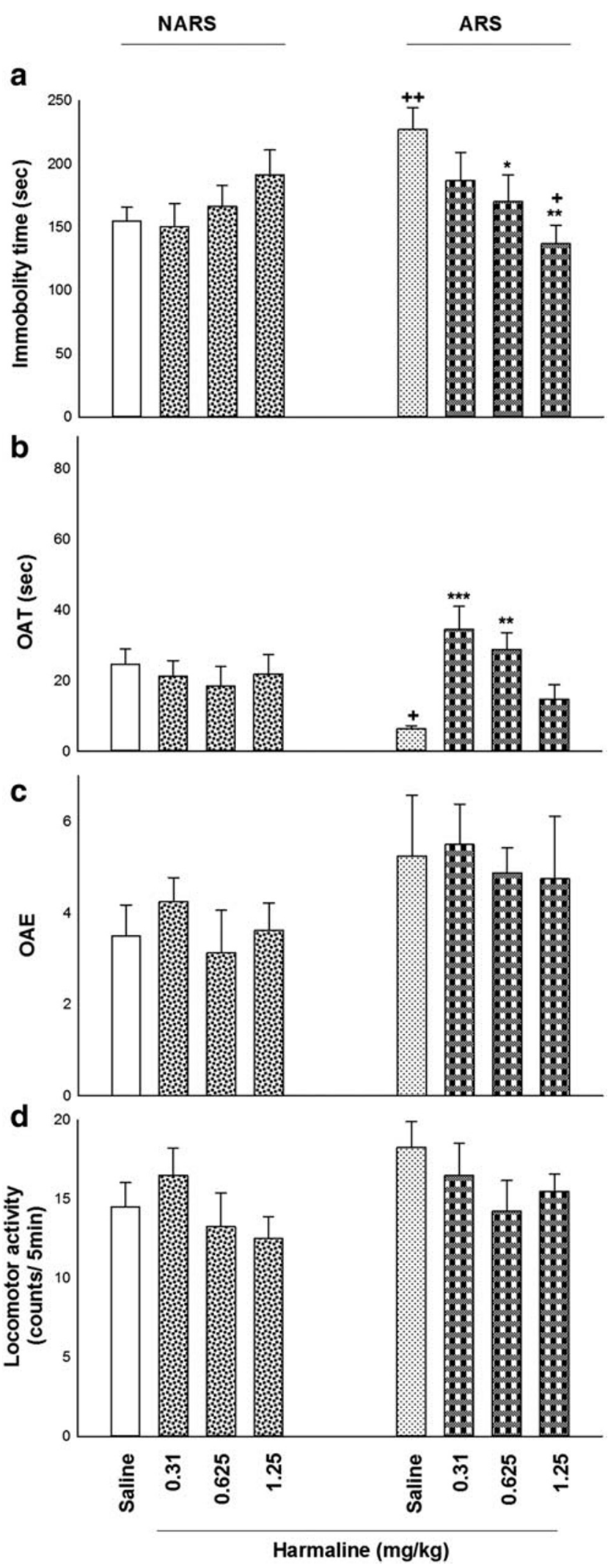

gated membrane channels; and regulation of cell energy homeostasis, mitochondrial functions, and oxygen-free radical scavenging as well as the ability to enhance brain-derived 
Fig. 3 The effects of cinanserin on depression- and anxiety-like responses in the NARS and ARS mice by the EPM and FST. (A) ARS, at a period of $4 \mathrm{~h}$, enhanced immobility time in the FST in comparison with the saline group. In ARS mice, i.c.v. microinjection of cinanserin (1, 2.5 , and $5 \mu \mathrm{g} /$ mouse) decreased immobility time in the FST compared to the control and respective control groups. (B) All doses of cinanserin increased OAT of ARS mice compared to the control and respective control groups. (C) Non-doses of cinanserin had no significant effect on $\mathrm{OAE}$ in comparison with the control group. (D) Cinanserin did not affect the locomotor activity at any used doses compared to the control group. Data are expressed as means $\pm \operatorname{SEM}\left(n=8\right.$ mice/group). ${ }^{* *} p<0.01$ and $* p<0.05$ in comparison with the saline/saline group. $++p<0.01$ and $+p<0.05$ compared to the saline/cinanserin group

neurotrophic factor (BDNF) (Abelaira et al. 2013; Dos Santos et al. 2016a, b; Moloudizargari et al. 2013; Savoldi et al. 2017; Splettstoesser et al. 2005). So it can be concluded that harmaline induced antidepressant- and anxiolytic-like effects in the ARS mice by stimulation of neurogenesis, induction of neuroprotective properties, and inhibition of MAO-A as well as enhancement of serotonin concentrations in the brain (Biradar et al. 2013; Dos Santos et al. 2016a; MoralesGarcia et al. 2017). However, there are contradictory reports about the effect of harmaline on the modulation of anxiety behavior. For example, harmaline induced anxiogenic effect at the lower doses, whereas it induced an anxiolytic effect at the higher dose (Hilber and Chapillon 2005; Wu et al. 2009).

Moreover, the results of the current study indicated that cinanserin microinjection into the left ventricle abolished ARS-produced depression- and anxiogenic-like behavior in the ARS mice. Our results proposed that 5-HT2 receptor antagonist and cinanserin induced antidepressant- and anxiolytic-like activity. The association between mood disorders, antidepressant responses, and 5-HT2 receptors is based on some preclinical and clinical investigations. The pathophysiology of depression- and anxiety-like responses may be related to a dysregulation of brain monoaminergic (5-HT, norepinephrine, and dopaminergic) neurotransmission. The monoaminergic neurons indicated complex functional and reciprocal interactions intimately related to 5-HT2 receptors. Preclinical researches indicated that 5-HT2 receptors represented promising targets in selective serotonin reuptake inhibitor (SSRI)-resistant depression. Especially, their pharmacological inactivation by the lack of selective 5-HT2 receptor ligand antagonism caused antidepressant-like behaviors per se and potentiated the behavioral effects of SSRIs (Quesseveur et al. 2012). Since anxiety is a symptom commonly observed in depressed patients after the acute application of SSRIs, the beneficial effects of 5-HT2 receptor antagonists on the antidepressant response could involve anxiolytic behaviors (Dekeyne et al. 2008). Researches revealed that the desensitization or downregulation of 5-HT2 receptors could be related to the therapeutic properties of some antidepressants (Gomez-Gil et al. 2004). Imaging studies supported this
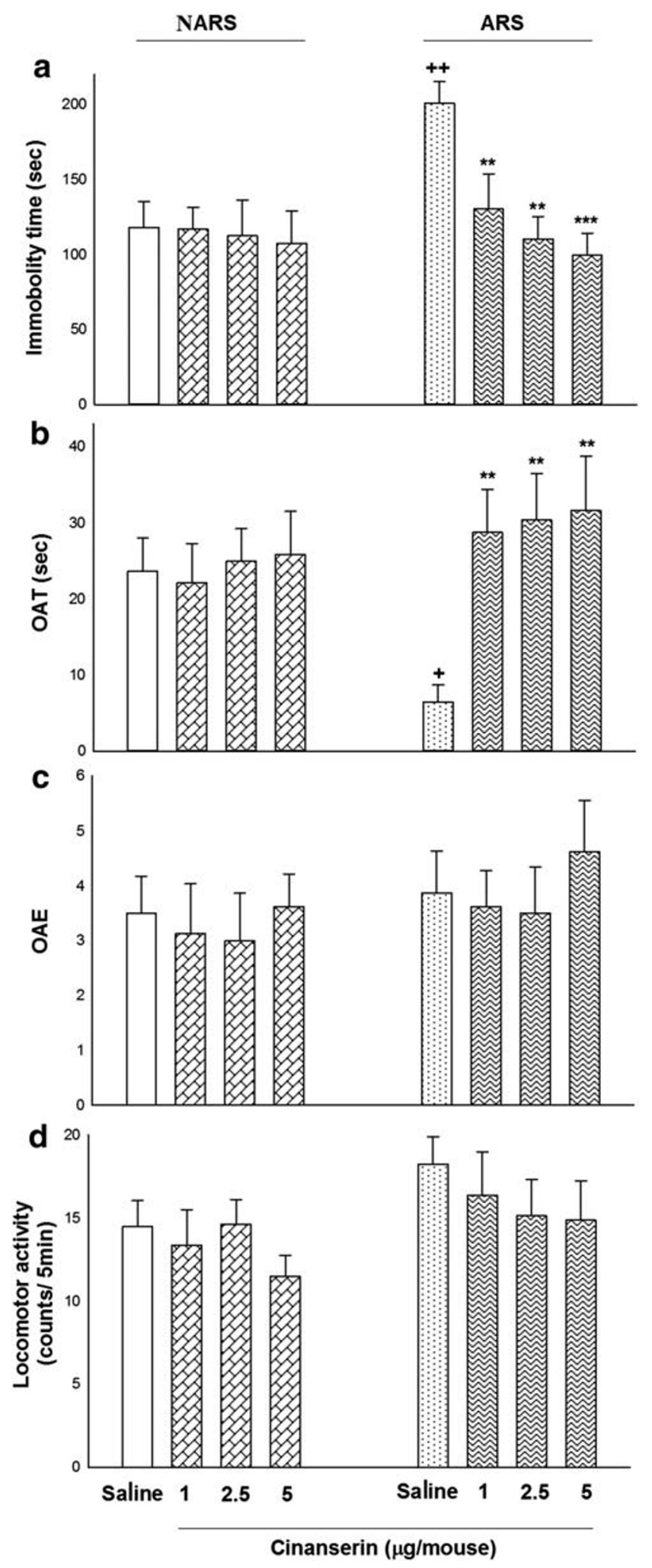

hypothesis because the downregulation of the 5-HT2 receptor was identified in the brain of depressed patients in response to SSRI treatment (Meyer et al. 2001). These reports raised the probability that $5-\mathrm{HT} 2$ receptor antagonists might induce 
Fig. 4 The effects of coadministration of harmaline and cinanserin on depression- and anxiety-correlated behaviors. (A) Co-administration of harmaline $(1.25 \mathrm{mg} / \mathrm{kg}$; i.p.) and cinanserin (5 $\mu \mathrm{g} /$ mouse; i.c.v.) decreased immobility time in the FST compared to saline, cinanserin, and ARS groups. (B) Co-treatment of harmaline $(1.25 \mathrm{mg} / \mathrm{kg})$ and cinanserin $(5 \mu \mathrm{g} /$ mouse $)$ increased OAT compared to saline, cinanserin, and ARS groups. (C) Co-application of harmaline $(1.25 \mathrm{mg} / \mathrm{kg})$ and cinanserin ( $5 \mu \mathrm{g} /$ mouse) enhanced OAE in comparison with saline, cinanserin, and ARS-treated groups. (D) Co-injection of harmaline $(1.25 \mathrm{mg} / \mathrm{kg})$ and cinanserin $(5 \mu \mathrm{g} /$ mouse $)$ did not alter locomotor activity compared to saline, cinanserin, and ARS groups. Data are expressed as means $\pm \operatorname{SEM}$ ( $n=8$ mice/group). $* * * p<0.001$ and $* p<0.05$ compared to the saline group. $+++p<0.001$ in comparison with the cinanserin group. $\# \# \equiv<0.001$ and $\# p<0.05$ in comparison with the ARS group
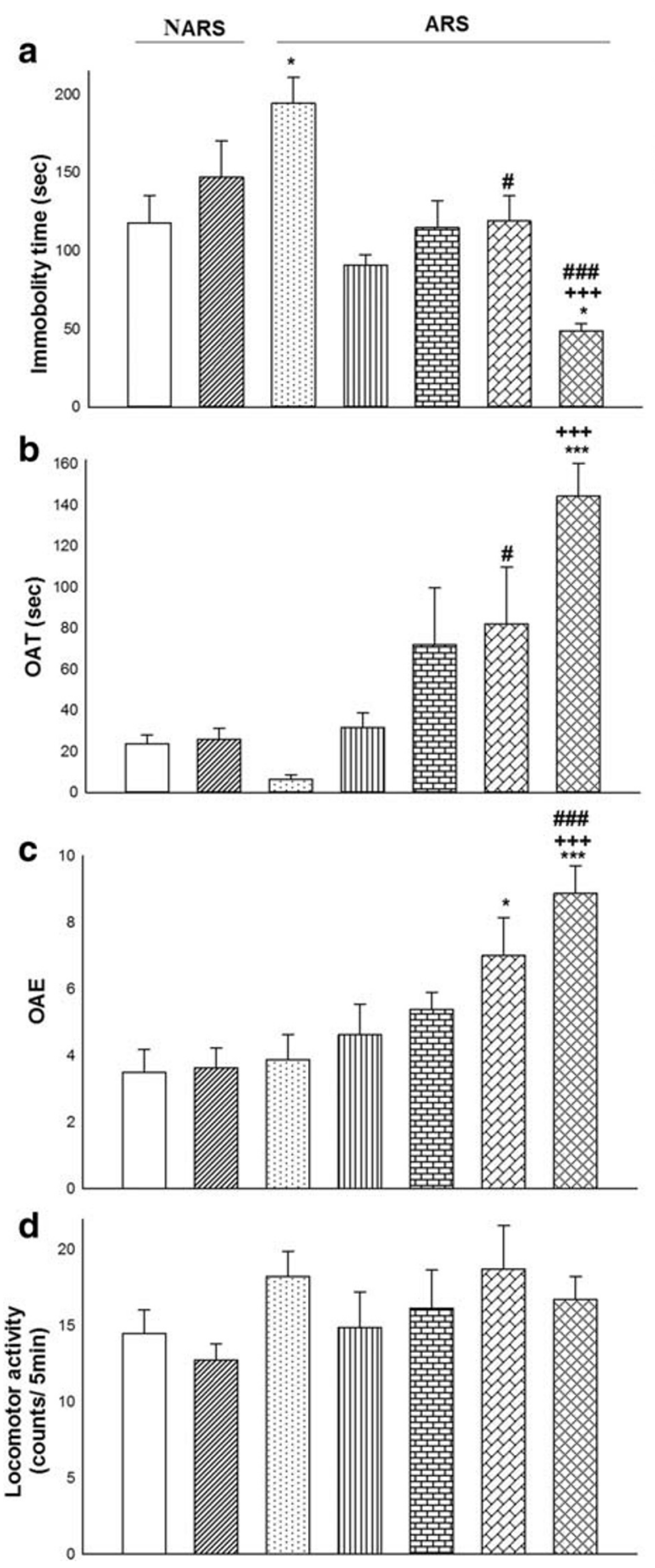

antidepressant-like activities (Guiard and Di Giovanni 2015). Also, the distribution and the behavioral properties of 5-HT2 receptors concerning depression- and anxiety-like responses in rodents supporting the idea that 5-HT2 receptor agonists/ antagonists might be useful in the treatment of these disorders (Samuels and Hen 2011).

In the next section of this research, we found that i.p. administration of harmaline $(1.25 \mathrm{mg} / \mathrm{kg})$ produced stronger antidepressant- and anxiolytic-like effects when accompanied by i.c.v. microinjection of cinanserin ( $5 \mu \mathrm{g} /$ mouse), suggesting that cinanserin could potentiate the harmaline responses in the ARS mice. The 5-HT2 receptor may mediate harmaline signaling in the brain. On the other hand, harmaline can bind to 5-HT2A receptors (Glennon et al. 2000; Grella et al. 2003). Thus, both cinanserin and harmaline activated 5-HT2 receptors in the brain (Dos Santos et al. 2016a; Glennon et al. 2000). Cinanserin through the desensitization or downregulation of 5-HT2 receptors and harmaline through MAO 


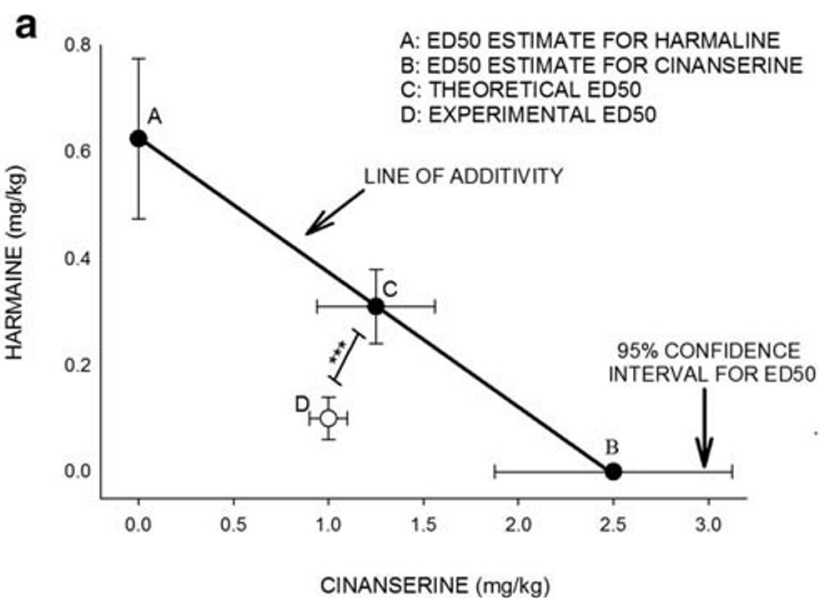

b
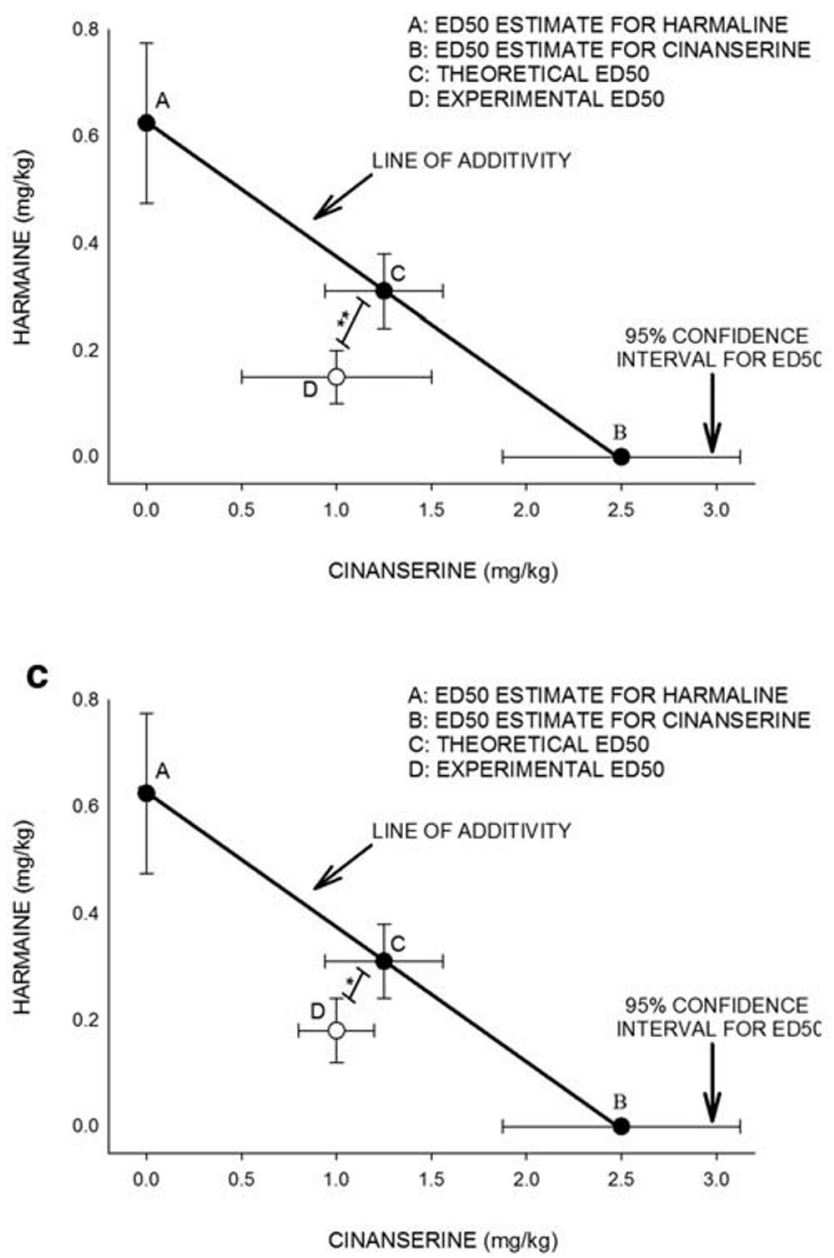

inhibition as well as enhancement of BDNF levels could induce antidepressant- and anxiolytic-like responses (Dos Santos et al. 2016a; Gomez-Gil et al. 2004). Moreover, the obtained results revealed that there was an interaction between the harmaline and 5-HT2 receptor on the modulation of depression- and anxiety-like behaviors in the ARS mice. More interestingly, we found the synergistic effect of
Fig. 5 The isobologram analysis of the effects of drug treatment revealed the synergistic effect of harmaline and cinanserin on the induction of antidepressive- and anxiolytic-like effects in the ARS mice. The foci A and B mean showed the ED50 of harmaline and cinanserin, respectively. In brief, the ED50 of each drug $(0.31 \mathrm{mg} / \mathrm{kg}$ for harmaline and $2.5 \mu \mathrm{g} /$ mouse for cinanserin) was measured by linear regression analysis. The oblique line between A and B is the theoretic additive effect line of harmaline and cinanserin administrations. The focus $\mathrm{C}$, in the middle of the line, is the theoretical ED50 of the drug combination, which is calculated from the individual drug ED50. The focus D, far under the line, is the experimental ED50 of drug combination, which is obtained after drug administration. Statistical analysis exhibited that there is a significant difference between experimental ED50 and theoretical ED50 points, indicating a synergistic effect of the administration of the drug ((A) for FST, (B) for \%OAT, and (C) for OAE in the ARS mice). ED50, effective dose 50

harmaline and cinanserin upon induction of antidepressantand anxiolytic-like properties, by isobolographic analysis. As mentioned previously, the modulation of 5-HT2 receptor activities may modulate depression- and anxiety-like behaviors in the ARS mice (Dos Santos et al. 2016a; Glennon et al. 2000). A probable mechanism for antidepressant- and anxiolytic-like effects induced by co-administration of harmaline and cinanserin might be due to the downregulation of 5-HT2 receptors and enhancement of BDNF levels and inhibition of MAO as well as modulation of benzodiazepine, dopamine, GABA, and opiate receptors (Abelaira et al. 2013; Dos Santos et al. 2016a, b; Savoldi et al. 2017; Splettstoesser et al. 2005). Although it is necessary to perform additional behavioral tests (for example sucrose preference test, open field test, and marble-burying test) to support the depressive and anxiety behaviors improved by the drugs, we cannot conduct new experiments at this time due to the pandemic COVID-19. Also in this research, the pharmacological studies which support the role of a specific sub-type of 5-HT2 receptor were not performed; hence, further studies are required to clarify the exact mechanisms of action between harmaline and 5-HT2 receptor on the modulation of depression and anxiety behaviors.

Acknowledgments We are thankful to all contributors for their participation.

\section{Compliance with ethical standards}

Conflict of interest The authors declare that they have no conflict of interest.

\section{References}

Abelaira HM, Reus GZ, Scaini G, Streck EL, Crippa JA, Quevedo J (2013) beta-Carboline harmine reverses the effects induced by stress on behaviour and citrate synthase activity in the rat prefrontal cortex. Acta neuropsychiatrica 25:328-333 
Abrams JK, Johnson PL, Hollis JH, Lowry CA (2004) Anatomic and functional topography of the dorsal raphe nucleus. Ann N Y Acad Sci 1018:46-57

Alijanpour S, Khakpai F, Ebrahimi-Ghiri M, Zarrindast MR (2019) Coadministration of the low dose of orexin and nitrergic antagonists induces an antidepressant-like effect in mice. Biomed Pharmacother 109:589-594

Bailey KR, Crawley JN (2009) Anxiety-related behaviors in mice. In: nd, Buccafusco JJ (eds) Methods of Behavior Analysis in Neuroscience (Frontiers in Neuroscience), Boca Raton (FL)

Biradar SM, Joshi H, Tarak KC (2013) Cerebroprotective effect of isolated harmine alkaloids extracts of seeds of Peganum harmala L. on sodium nitrite-induced hypoxia and ethanol-induced neurodegeneration in young mice. Pak J Biol Sci 16:1687-1697

Callaway JC, Brito GS, Neves ES (2005) Phytochemical analyses of Banisteriopsis caapi and Psychotria viridis. J Psychoactive Drugs 37:145-150

Celada P, Puig M, Amargos-Bosch M, Adell A, Artigas F (2004) The therapeutic role of 5-HT1A and 5-HT2A receptors in depression. J Psychiatry Neurosci 29:252-265

Chiba S, Numakawa T, Ninomiya M, Richards MC, Wakabayashi C, Kunugi H (2012) Chronic restraint stress causes anxiety- and depression-like behaviors, downregulates glucocorticoid receptor expression, and attenuates glutamate release induced by brainderived neurotrophic factor in the prefrontal cortex. Prog NeuroPsychopharmacol Biol Psychiatry 39:112-119

Christiansen SH, Olesen MV, Wortwein G, Woldbye DP (2011) Fluoxetine reverts chronic restraint stress-induced depression-like behaviour and increases neuropeptide $\mathrm{Y}$ and galanin expression in mice. Behav Brain Res 216:585-591

Cunningham AM, Santos TL, Gutzeit VA, Hamilton H, Hen R, Donaldson ZR (2019) Functional interrogation of a depressionrelated serotonergic single nucleotide polymorphism, rs6295, using a humanized mouse model. ACS Chem Neurosci 10:3197-3206

de Kloet ER, Joels M, Holsboer F (2005) Stress and the brain: from adaptation to disease. Nat Rev Neurosci 6:463-475

Dekeyne A, Mannoury la Cour C, Gobert A, Brocco M, Lejeune F, Serres F, Sharp T, Daszuta A, Soumier A, Papp M, Rivet JM, Flik G, Cremers TI, Muller O, Lavielle G, Millan MJ (2008) S32006, a novel 5-HT2C receptor antagonist displaying broad-based antidepressant and anxiolytic properties in rodent models. Psychopharmacology 199:549-568

Dos Santos RG, Osorio FL, Crippa JA, Hallak JE (2016a) Antidepressive and anxiolytic effects of ayahuasca: a systematic literature review of animal and human studies. Braz J Psychiatry 38:65-72

Dos Santos RG, Osorio FL, Crippa JA, Riba J, Zuardi AW, Hallak JE (2016b) Antidepressive, anxiolytic, and antiaddictive effects of ayahuasca, psilocybin and lysergic acid diethylamide (LSD): a systematic review of clinical trials published in the last 25 years. Ther Adv Psychopharmacol 6:193-213

Glennon RA, Dukat M, Grella B, Hong S, Costantino L, Teitler M, Smith C, Egan C, Davis K, Mattson MV (2000) Binding of beta-carbolines and related agents at serotonin (5-HT(2) and 5-HT(1A)), dopamine $(\mathrm{D}(2))$ and benzodiazepine receptors. Drug Alcohol Depend 60: $121-132$

Gomez-Gil E, Gasto C, Carretero M, Diaz-Ricart M, Salamero M, Navines R, Escolar G (2004) Decrease of the platelet 5-HT2A receptor function by long-term imipramine treatment in endogenous depression. Hum Psychopharmacol 19:251-258

Grella B, Teitler M, Smith C, Herrick-Davis K, Glennon RA (2003) Binding of beta-carbolines at 5-HT(2) serotonin receptors. Bioorg Med Chem Lett 13:4421-4425

Grizzell JA, Iarkov A, Holmes R, Mori T, Echeverria V (2014) Cotinine reduces depressive-like behavior, working memory deficits, and synaptic loss associated with chronic stress in mice. Behav Brain Res 268:55-65
Guiard BP, Di Giovanni G (2015) Central serotonin-2A (5-HT2A) receptor dysfunction in depression and epilepsy: the missing link? Front Pharmacol 6:46

Herman JP, McKlveen JM, Solomon MB, Carvalho-Netto E, Myers B (2012) Neural regulation of the stress response: glucocorticoid feedback mechanisms. Braz J Med Biol Res 45:292-298

Hilber P, Chapillon P (2005) Effects of harmaline on anxiety-related behavior in mice. Physiol Behav 86:164-167

Hill MN, Sun JC, Tse MT, Gorzalka BB (2006) Altered responsiveness of serotonin receptor subtypes following long-term cannabinoid treatment. Int J Neuropsychopharmacol 9:277-286

Jensen NH, Cremers TI, Sotty F (2010) Therapeutic potential of 5-HT2C receptor ligands. ScientificWorldJournal 10:1870-1885

Khan SI, Abourashed EA, Khan IA, Walker LA (2004) Transport of harman alkaloids across Caco-2 cell monolayers. Chem Pharm Bull 52:394-397

Kolar D, Kolar MV (2016) Critical review of available treatment options for treatment refractory depression and anxiety - clinical and ethical dilemmas. Med Pregl 69:171-176

Leysen JE (2004) 5-HT2 receptors. Curr Drug Targets CNS Neurol Disord 3:11-26

Li S, Fan YX, Wang W, Tang YY (2012) Effects of acute restraint stress on different components of memory as assessed by objectrecognition and object-location tasks in mice. Behav Brain Res 227:199-207

Li S, Cheng X, Wang C (2017a) A review on traditional uses, phytochemistry, pharmacology, pharmacokinetics and toxicology of the genus Peganum. J Ethnopharmacol 203:127-162

Li S, Teng L, Liu W, Cheng X, Jiang B, Wang Z, Wang C (2017b) Interspecies metabolic diversity of harmaline and harmine in in vitro 11 mammalian liver microsomes. Drug Test Anal 9:754 768

Li S, Zhang Y, Deng G, Wang Y, Qi S, Cheng X, Ma Y, Xie Y, Wang C (2017c) Exposure characteristics of the analogous beta-carboline alkaloids harmaline and harmine based on the efflux transporter of multidrug resistance protein 2. Front Pharmacol 8:541

Meyer JH, Kapur S, Eisfeld B, Brown GM, Houle S, DaSilva J, Wilson AA, Rafi-Tari S, Mayberg HS, Kennedy SH (2001) The effect of paroxetine on 5-HT(2A) receptors in depression: an [(18)F] setoperone PET imaging study. Am J Psychiatry 158:78-85

Millan MJ, Marin P, Bockaert J, Mannoury la Cour C (2008) Signaling at G-protein-coupled serotonin receptors: recent advances and future research directions. Trends Pharmacol Sci 29:454-464

Moloudizargari M, Mikaili P, Aghajanshakeri S, Asghari MH, Shayegh J (2013) Pharmacological and therapeutic effects of Peganum harmala and its main alkaloids. Pharmacogn Rev 7:199-212

Morales-Garcia JA, de la Fuente RM, Alonso-Gil S, Rodriguez-Franco MI, Feilding A, Perez-Castillo A, Riba J (2017) The alkaloids of Banisteriopsis caapi, the plant source of the Amazonian hallucinogen Ayahuasca, stimulate adult neurogenesis in vitro. Sci Rep 7: 5309

Nasehi M, Jamshidi-Mehr M, Khakpai F, Zarrindast MR (2014) Possible involvement of CA1 5-HT1B/1D and 5-HT2A/2B/2C receptors in harmaline-induced amnesia. Pharmacol Biochem Behav 125:70-77

Nasehi M, Morteza-Zadeh P, Khakpai F, Zarrindast MR (2016) Additive effect of harmane and muscimol for memory consolidation impairment in inhibitory avoidance task. Neuroscience 339:287-295

Nasehi M, Ghadimi F, Khakpai F, Zarrindast MR (2017a) Interaction between harmane, a class of beta-carboline alkaloids, and the CA1 serotonergic system in modulation of memory acquisition. Neurosci Res 122:17-24

Nasehi M, Ostadi E, Khakpai F, Ebrahimi-Ghiri M, Zarrindast MR (2017b) Synergistic effect between D-AP5 and muscimol in the nucleus accumbens shell on memory consolidation deficit in adult male Wistar rats: an isobologram analysis. Neurobiol Learn Mem 141:134-142 
Nejati S, Khakpai F, Zarrindast MR (2020) Synergistic effect between citalopram and citicoline on anxiolytic effect in non-sensitized and morphine-sensitized mice: an isobologram analysis. Brain Res 1734:146701

Paxinos G, Franklin KBJ (2001) The mouse brain in stereotaxic coordinates, 2nd edn. Academic Press, San Diego

Pfau W, Skog K (2004) Exposure to beta-carbolines norharman and harman. J Chromatogr B Anal Technol Biomed Life Sci 802:115126

Quesseveur G, Nguyen HT, Gardier AM, Guiard BP (2012) 5-HT2 1igands in the treatment of anxiety and depression. Expert Opin Investig Drugs 21:1701-1725

Samuels BA, Hen R (2011) Neurogenesis and affective disorders. Eur J Neurosci 33:1152-1159

Savoldi R, Polari D, Pinheiro-da-Silva J, Silva PF, Lobao-Soares B, Yonamine M, Freire FAM, Luchiari AC (2017) Behavioral changes over time following ayahuasca exposure in zebrafish. Front Behav Neurosci 11:139

Shoji H, Miyakawa T (2020) Differential effects of stress exposure via two types of restraint apparatuses on behavior and plasma corticosterone level in inbred male BALB/cAJcl mice. Neuropsychopharmacol Rep 40:73-84
Splettstoesser F, Bonnet U, Wiemann M, Bingmann D, Busselberg D (2005) Modulation of voltage-gated channel currents by harmaline and harmane. Br J Pharmacol 144:52-58

Tiller JW (2013) Depression and anxiety. Med J Aust 199:S28-S31

Vargas-Lopez V, Torres-Berrio A, Gonzalez-Martinez L, Munera A, Lamprea MR (2015) Acute restraint stress and corticosterone transiently disrupts novelty preference in an object recognition task. Behav Brain Res 291:60-66

Voorhees JL, Tarr AJ, Wohleb ES, Godbout JP, Mo X, Sheridan JF, Eubank TD, Marsh CB (2013) Prolonged restraint stress increases IL-6, reduces IL-10, and causes persistent depressive-like behavior that is reversed by recombinant IL-10. PLoS One 8:e58488

Wu C, Jiang XL, Shen HW, Yu AM (2009) Effects of CYP2D6 status on harmaline metabolism, pharmacokinetics and pharmacodynamics, and a pharmacogenetics-based pharmacokinetic model. Biochem Pharmacol 78:617-624

Publisher's note Springer Nature remains neutral with regard to jurisdictional claims in published maps and institutional affiliations. 